
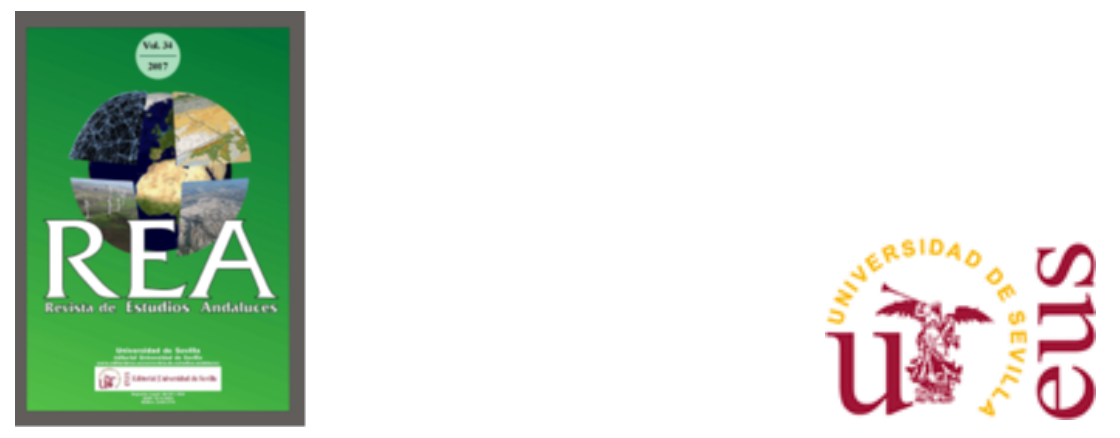

Revista de Estudios Andaluces (REA)

e-ISSN: $2340-2776$.

REA Vol. 34 (2017). http://dx.doi.org/10.12795/rea.2017.i34

\title{
La Protección Medioambiental: Predicar con el Ejemplo
}

\author{
María José Vázquez-Cueto \\ Universidad de Sevilla \\ pepi@us.es \\ Rosario Asián-Chaves \\ Universidad de Sevilla \\ rasian@us.es \\ Enriqueta Camacho-Peñalosa \\ Universidad de Sevilla \\ enriquet@us.es \\ Inmaculada Masero-Moreno \\ Universidad de Sevilla \\ imasero@us.es
}

Environmental Protection: Leading by Example

Formato de cita / Citation: Vázquez-Cueto, Ma José; Asián-Chaves, Rosario; CamachoPeñalosa, Enriqueta; Masero-Moreno, Inmaculada (2017). La Protección Medioambiental: Predicar con el Ejemplo. Revista de Estudios Andaluces, vol. 34 (1), 1-25. http://dx.doi.org/10.12795/rea.2017.i34.01

Enlace artículo / to link to this article: http://dx.doi.org/10.12795/rea.2017.i34.01

\footnotetext{
(c) (i) $\ominus$

SinObraDerivada 4.0 Internacional

http://editorial.us.es/es/revista-de-estudios-andaluces

https://ojs.publius.us.es/ojs/index.php/REA
} 


\title{
La Protección Medioambiental: Predicar con el Ejemplo
}

\author{
Environmental Protection: Leading by Example
}

\author{
María José Vázquez-Cueto \\ Universidad de Sevilla \\ pepi@us.es \\ Rosario Asián-Chaves \\ Universidad de Sevilla \\ rasian@us.es \\ Enriqueta Camacho-Peñalosa \\ Universidad de Sevilla \\ enriquet@us.es \\ Inmaculada Masero-Moreno \\ Universidad de Sevilla \\ imasero@us.es
}

Recibido: 12 de julio, 2016

Revisado: 12 de enero, 2017

Aceptado: 22 de febrero, 2017

Resumen

La preocupación por el cuidado del medioambiente es generalizada, probablemente porque se considera que éste nos pertenece, nos afecta y, por tanto, nos concierne a todas las personas. La buena predisposición teórica hacia políticas o iniciativas que promueven buenos comportamientos ambientales se debilita al conocer los gastos asociados a la recuperación y mantenimiento del medioambiente, máxime cuando se toma conciencia de la repercusión directa para el bolsillo. Este trabajo pone de manifiesto la discrepancia entre la preocupación medioambiental y lo que estamos dispuestos a pagar para paliar los daños medioambientales. A partir de los datos del Ecobarómetro Andaluz (EBA) y la Encuesta de Realidad Social en Andalucía (ERSA), realizamos análisis descriptivos y contrates paramétricos y no paramétricos. Observamos la escasa materialización en euros de la alta preocupación medioambiental, encontrando así que la población analizada está muy lejos de predicar con el ejemplo y que otorga un valor nulo a su conciencia medioambiental. Además, hemos analizado separadamente por sexo encontrando ciertas diferencias dignas de mención, según género.

Palabras clave: Medioambiente, disposición al pago, género, Andalucía. 


\begin{abstract}
The attention and care to the environment is an agreed and consensus worry and, apart from generational interests, probably it is because it belongs to everyone, it affects to everyone and it concerns to everyone. The citizenship usually receives with claimed enthusiasm and they answer positively to the initiatives that promote good environmental behaviors. However, this good theoretical predisposition weakens on having known the expenses associated with the recovery and maintenance of the environment, especially when the citizens become aware of the direct repercussion for their pocket. This work reveals the discrepancy between the environmental worry and the money they are willing to pay to relieve the above-mentioned worry. It tries to put price to the environmental concern and for these reasons the take references from the Andalusian population. With the analysis of the information provided by the Andalusian Ecobarometer (EBA) and the Social Reality Survey in Andalusia (ERSA) we could observe the limited materialization in Euros of the high environmental worry, finding that the analyzed population is very far from preaching with the example and that it gives a void value to his environmental conscience. We have also made the analysis separately for different sex finding unlikeness by gender, that, even if they are small, they ought to be mentioned.
\end{abstract}

Keywords: Environmental, willingness to pay, gender, Andalusia.

Revista de Estudios Andaluces, vol. 34, núm. 1 (2017) pp. 1-25. e-ISSN: 2340-2776 http://dx.doi.org/10.12795/rea.2017.i34.01 


\section{INTRODUCCIÓN}

Existen numerosos estudios que ponen de manifiesto que los países han crecido a espaldas del deterioro medioambiental. De hecho, se muestra que durante el Siglo XX la población del planeta se multiplicó por cuatro mientras la producción industrial lo hizo por 40 (Arrow, K. et al., 2004). Tendríamos que remontarnos a la revolución industrial del siglo XIX, cuyo impacto dura hasta nuestros días, marcando la forma de vida y costumbres de nuestra sociedad, para datar el principio de este fenómeno, cuyos efectos han provocado un deterioro en nuestro entorno que se ha ido evidenciando cada vez más en las últimas décadas del siglo XX. Sin embargo, hace relativamente poco tiempo que los países tomaron conciencia de la necesidad de un desarrollo sostenible, demostrando tanto teórica como empíricamente que ambos conceptos no son contrapuestos y que es posible un crecimiento sostenible.

En la década de los sesenta del siglo pasado, surge el movimiento ecologista para luchar contra las agresiones que el desarrollo económico e industrial mundial había causado al ecosistema. Posteriormente, su atención se centró en la concienciación de las poblaciones, cuya actitud diaria resulta tan contaminante y agresiva contra su propio medioambiente como la producida por las industrias.

A partir de la Cumbre de Río en 1992, se firma una declaración entre los gobiernos participantes en la Cumbre de las Naciones Unidas para el Medioambiente y el Desarrollo, en la que procuran alcanzar acuerdos internacionales en los que se respeten los intereses de todos y se proteja la integridad del sistema ambiental y de desarrollo mundial.

Una de las cuestiones más de moda desde finales del siglo $X X$, según la literatura contemporánea sobre el tema, es según Aguilera y Alcántara (1994) la de la valoración monetaria de los beneficios y costes ambientales. Y ellos recopilan algunas de las principales aportaciones en este sentido, relativas al análisis coste-beneficio y el proceso de revisión de la contabilidad nacional, tanto en lo concerniente a la valoración del llamado capital natural como a la corrección del PIB y/o el PNB como indicadores de bienestar social.

En la primera década del siglo XXI, se considera que hay un consenso por parte de la ciudadanía acerca de la necesidad de atender y cuidar el medioambiente. Ahora bien, esta hipotéticamente buena inclinación a favor de este tema se atenúa en el momento en que los gastos que conllevan la reparación y el sostenimiento del medioambiente son conocidos. Existe una amplia literatura científica que ahonda en esta afirmación y, a través de modelos estadísticos, pone de manifiesto algunas características socioeconómicas y demográficas que conectan la disposición teórica con su puesta en práctica.

Revista de Estudios Andaluces, vol. 34, núm. 1 (2017) pp. 1-25. e-ISSN: 2340-2776

http://dx.doi.org/10.12795/rea.2017.i34.01

\section{(c) (i) $(9)$}

SinObraDerivada 4.0 Internacional 
Las políticas ambientales están dirigidas a mejorar el bienestar de las personas y la sustentabilidad ambiental de la economía y también están enfocadas en vigilar el comportamiento de las empresas y los hogares. El indicador de la OCDE sobre políticas de rigurosidad ambiental ${ }^{1}$ muestra que las políticas ambientales se han vuelto más implacables en las últimas dos décadas. Según los datos ofrecidos por la OCDE, el indicador de rigurosidad ambiental se situaba en el 0,9 para los países de la OCDE $(0,8$ para España) en el año 1990, elevándose en el 2012, último dato publicado, 2,8 (2,2 en España).

Una buena política medioambiental funcionará en función del grado de respuesta de la ciudadanía (Freeman, A.M. et al., 1992). Según el conocimiento de estos autores, no existe hasta el momento un estudio que vincule de manera general la preocupación que dicen sentir las poblaciones por su entorno natural con los sacrificios que están dispuestos a realizar para preservarlo y mantenerlo o mejorarlo. Los recursos públicos son escasos, además de tener usos alternativos, por lo que resulta esencial saber cuál es la disposición a pagar de las personas por proyectos que se dirijan a la mejora de la calidad del medioambiente. El método más usual en este tipo de investigaciones es el de Valoración Contingente (Jürgen, U.L., 2006). Generalmente cuando se trata de poner precio a determinada medida se trabaja con el método de valoración contingente o el método de elección contingente, con los que, a través de encuestas diseñadas en forma de pregunta directa o en forma de elección u ordenación de alternativas, se trata de determinar la disposición a pagar de los individuos por un bien concreto, y no por el que otorgan a los bienes o servicios medioambientales en su acepción más general. Se puede encontrar, además, abundante literatura sobre la exigua cantidad que se está dispuesto a pagar para conservar ese bien tan preciado y concreto sobre el que se pregunta.

Este trabajo trata de paliar este hueco poniendo en relación la importancia que se otorga al medioambiente con la predisposición a contribuir monetariamente a la preservación y mantenimiento del mismo, centrándonos para ello en la Comunidad Autónoma de Andalucía.

Para dicha Comunidad disponemos del Ecobarómetro andaluz y la Encuesta de la Realidad Social Andaluza que nos van a permitir perfilar nuestra hipótesis de partida y contrastarla estadísticamente. Así, tras esta introducción y el siguiente epígrafe en el que se plantea la pertinencia de realizar un estudio de las diferencias de género en las cuestiones relativas a la valoración de las cuestiones ambientales, presentamos en el epígrafe tres las características de ambas encuestas, fuentes de nuestros datos, junto con los ítems utilizados y la metodología a seguir. El epígrafe cuarto presenta los resultados obtenidos, que dan origen al análisis de los condicionantes que han podido conducir a los mismos. Terminando el cinco con las conclusiones extraídas.

\footnotetext{
${ }^{1}$ La política de rigurosidad ambiental se define como el costo a las empresas por contaminar inducido dentro de una política o instrumento de política. Valores más altos representan una política más estricta.
}

Revista de Estudios Andaluces, vol. 34, núm. 1 (2017) pp. 1-25. e-ISSN: 2340-2776 http://dx.doi.org/10.12795/rea.2017.i34.01 


\section{RELACIÓN MEDIOAMBIENTE Y GÉNERO}

Las preocupaciones ambientales han aumentado de manera generalizada en el pensamiento y las conductas sociales desde hace algún tiempo. Cada vez es mayor la exigencia que realiza la población de más calidad en las cuestiones ambientales. Asimismo, a nivel mundial es creciente la percepción que existe acerca de la cada vez más ajustada correlación entre las cuestiones ambientales y los asuntos de índole económico, demográfico y social, así como acerca de la exigencia de hallar respuestas holistas y sistémicas a todos ellos. Todo esto ha concurrido con la apreciación de que, desde finales del siglo XX, la sociedad global tiene el desafío del colapso de un modelo de desarrollo que, además de injusto, se presenta indefendible e inadmisible en el medio y largo plazo. Este modelo se distingue por ser dañino para los sistemas naturales y además presentar para las personas desigualdades y falta de equidad. Además, dicho modelo es el resultado contiguo de significativas privaciones estructurales en la adopción de las prácticas de desarrollo (Rico, M. N., 1998).

Precisamente, el desarrollo sostenible además de representar una condición y requisito, además es asimismo la ocasión histórica de inducir el progreso de una economía con mayores niveles de equidad. En la discusión en torno al concepto de sostenibilidad del desarrollo que se lleva a cabo en los últimos años, se arguye que hay una correspondencia entre sostenibilidad y el logro del Desarrollo Humano que funciona en ambos sentidos, siendo cada uno de ellos medio para la consecución del otro. En los últimos tiempos, se ha puesto el acento fundamentalmente en el principio de "resiliencia" del ecosistema, así como en la facultad de los seres humanos para transformar sus subsistencias para de este modo hacer posible la reparación de las crisis. De acuerdo con Rico, M. N. (1998), esto responde a una visión sistémica y multidimensional del desarrollo en el que la solidaridad intergeneracional, la equidad y las consideraciones a largo plazo son elementos ineludibles. Esta misma autora destaca, entre los avances habidos en esta dirección, el avance hacia un patrón extenso e integrador. Se trataría del avance desde una orientación técnica y física hacia una perspectiva más social e inclusive política, y de esta forma convertir a la equidad en un mecanismo clave de la sostenibilidad (Asián, R., 2013).

Junto a ello, el hecho de haber comprendido las peculiaridades contraídas por la colaboración de los variados grupos de mujeres en el desarrollo, ha hecho que la unión entre las relaciones de género, el medioambiente y la sostenibilidad pase a ser destacada e imprescindible, y pase a formar parte esencial en las políticas internacionales, fundamentalmente a partir de las Estrategias de Nairobi orientadas hacia el futuro para el adelanto de la mujer.

En este sentido es preciso destacar la aportación inestimable que formalizó la Organización de Mujeres para el Medioambiente y el Desarrollo explicando la Agenda

Revista de Estudios Andaluces, vol. 34, núm. 1 (2017) pp. 1-25. e-ISSN: 2340-2776 http://dx.doi.org/10.12795/rea.2017.i34.01

\section{(c) (i) (3)}

SinObraDerivada 4.0 Internacional 
de las mujeres para los dirigentes implicados en la Conferencia de Río. Además de la progresiva percepción internacional acerca de las cuestiones de género $y$ medioambiente, el apremio que realizan las diversas redes y grupos de mujeres terminó plasmándose en el principio 20 de la Declaración de Río que dice: "Las mujeres juegan un rol principal en el manejo ambiental y el desarrollo. Por esa razón su participación total es imprescindible para lograr un desarrollo sustentable" (Naciones Unidas, 1992). El vínculo entre género-medioambiente-desarrollo sostenible adquiere un puesto vital en la Cuarta Conferencia Mundial sobre la Mujer: Acción para la Igualdad, el Desarrollo y la Paz, que tuvo lugar en Beijing y en el Foro de ONGs que se ejecutó simultáneamente. Actualmente, el género y el medioambiente subsisten como asuntos que atraviesan de manera transversal todas las esferas de la gestión pública.

Resulta curioso, y así lo queremos destacar, como ambos movimientos, la problemática del género y la medioambiental, siendo tan distintos, han seguido caminos paralelos. Así, y como recoge Levy, C. (1992), ambos necesitan de actuaciones sociales, lideradas por los feministas los primeros y los ecologistas los últimos, para llamar la atención de los Gobiernos, y eso pese a las distintas recomendaciones recogidas en diversas Conferencias Mundiales. Gracias a ello empezaron a crearse departamento, programas y proyectos específicos para paliar la marginalización de las que ambos adolecían en las principales corrientes de desarrollo. Aun así, hoy en día siguen compitiendo por los escasos recursos humanos y materiales de los que disponen, siguiendo siendo válido los comentarios sobre ello que se recogen en BID, $1996^{2}$.

El género representa una labor fundamental en la reciprocidad entre las personas y el ambiente (Middlestadt, S. et al., 2001). La justificación de la relevancia de contemplar la cuestión de género en las cuestiones ambientales se plantea desde la necesidad de entender la reciprocidad que sostienen con el medioambiente mujeres y hombres, y que no solo se presenta mediante sus propósitos, sino esencialmente por medio de sus actos. Algunos estudiosos del tema, véase por ejemplo Stern, P. et al. (1993), Mellor, M. (2002) y González (2005), opinan que las mujeres tienen mayor tendencia a actuaciones en pro del medioambiente que los hombres, mientras que otros autores sostienen lo contrario. Así, Mostafa, M. (2007) halló que ellos se revelan más inquietados por las cuestiones ambientales y presentan un talente más proclive que las mujeres. El hecho de que la mayor parte de las personas encargadas de tomar las decisiones medioambientales sean hombres y la mayoría de la gente que se somete a dichas decisiones sean mujeres es la manifestación más evidente de que el género se vincula al medioambiente. Aunque hay que tener en cuenta que este asunto es más complejo a causa del influjo de variables transversales.

\footnotetext{
2 BID (Banco Interamericano de Desarrollo) (1996), La mujer en las Américas. Cómo cerrar la brecha entre los géneros, Washington, D.C. (citado en Rico, M. N., 1998).
}

Revista de Estudios Andaluces, vol. 34, núm. 1 (2017) pp. 1-25. e-ISSN: 2340-2776 http://dx.doi.org/10.12795/rea.2017.i34.01 


\section{DATOS Y METODOLOGÍA}

El Ecobarómetro (EBA), encuesta de periodicidad anual elaborada actualmente por la Red de Información de Andalucía con la colaboración del Instituto de Estudios Sociales de Andalucía (IESA), en el marco del Decreto Rediam 347/2011, proporciona para Andalucía datos y aclaraciones sobre el valor que la ciudadanía concede a los asuntos medioambientales. A raíz de la crisis económica, los ciudadanos, se muestran más preocupados por el desempleo y las perspectivas económicas, desplazando a puestos inferiores su preocupación medioambiental. Así, si en su edición correspondiente a 2001, resultaba que en torno al $25 \%$ de los andaluces consideraban como uno de los tres principales problemas de Andalucía la cuestión medioambiental, en la EBA de 2009 solo lo consideraba así el 11,9\%. A pesar de estos bajos porcentajes, los temas relacionados con el medioambiente continúan ocupando un lugar intermedio entre las preocupaciones de los andaluces y andaluzas. Así, el 60,5\% de las personas encuestadas se declararon bastante preocupadas por el medioambiente.

Se han utilizado los datos del EBA de 2009, aunque existan ediciones posteriores, para poder completar dichos datos con los ofrecidos por la "Encuesta de Realidad Social en Andalucía" (ERSA), elaborada en 2009 por el Centro de Estudios Andaluces, que dedicó uno de sus módulos rotatorios al medioambiente ${ }^{3}$. En ella se marca como uno de los aspectos importantes de la conciencia ambiental de la población andaluza la demanda de políticas medioambientales, en particular se valora su opinión sobre el gasto público en diferentes partidas. Según esta encuesta, el $46,1 \%$ de la ciudadanía andaluza opina que se debe "gastar más" en la protección del medioambiente. Este porcentaje ocupa el tercer puesto por la cola con respecto a otras partidas, lo que confirma los datos de la EBA respecto a que el medioambiente deja de ser uno de los tres principales problemas de Andalucía. Sin embargo, esta circunstancia no tiene por qué indicar la falta de conciencia ambiental de los andaluces, ya que no muestra hasta qué punto están dispuestos a realizar sacrificios personales por el medioambiente.

Este trascendental aspecto de la conciencia ambiental será valorado utilizando la ERSA como fuente primaria, a la que nos remitimos, una vez recopilada la información sobre la evolución de la importancia que tiene el mantenimiento y recuperación del medioambiente para los andaluces, utilizando una metodología cuantitativa. Comenzamos con una fase exploratoria en la que, examinada la literatura, elaboramos nuestro presupuesto teórico de partida, que nos permite conocer los métodos que se han aplicado exitosamente para analizar el problema, así como las variables necesarias para nuestro estudio. Con esto refinamos nuestras hipótesis y diseñamos la investigación que, en una primera fase será descriptiva para, posteriormente, utilizar la

\footnotetext{
${ }^{3}$ ERSA: III.BLOQUE DE MEDIOAMBIENTE (MÓDULO ROTATORIO).
} 
inferencia estadística, probando nuestras hipótesis con análisis paramétricos y no paramétricos y la utilización del software SPSS.

Nuestra hipótesis de partida es doble. Por un lado, planteamos que existe una brecha entre la preocupación que la persona declara por el medioambiente y la disposición que tiene a contribuir monetariamente a su mantenimiento. $\mathrm{Y}$, por otro, por las razones expuestas en el epígrafe anterior, proponemos que esta brecha es distinta según el sexo, debido a cuestiones de género.

Así, con el objeto de monetizar la conciencia y preocupación que la población andaluza muestra por el medioambiente vamos a utilizar las respuestas en la ERSA al ítem P2006: "Le voy a mencionar diversos capítulos de gasto público. Dígame, por favor, si a Ud. le gustaría que se gastara más o menos en cada uno de ellos", en el que ofrece a las personas encuestadas que elija entre una de las cinco categorías: "gastar mucho más", "gastar más", "gastar lo mismo que ahora", "gastar menos" y "gastar mucho menos", ordenadas del 1 al 5 respectivamente. El análisis descriptivo de las respuestas nos permitirá situar al medioambiente frente a otras partidas del gasto público.

Esta predisposición "teórica" se contrastará "empíricamente" analizando los resultados obtenidos sobre la disposición individual al pago manifestado a través de los siguientes ítems de la ERSA:

- 3002.a): “¿Hasta qué punto estaría Ud. a favor de pagar precios más elevados para proteger el medioambiente?"

- 3002.b): “¿Hasta qué punto estaría usted a favor de pagar más impuestos para proteger el medioambiente?"

En el que para ambos se pide a la persona encuestada que elija una de entre cinco categorías: "muy a favor", "bastante a favor", "ni a favor ni en contra", "bastante en contra" y "muy en contra", ordenadas respectivamente de 1 a 5.

Con objeto de validar la significatividad de las conclusiones que se extraen de los posteriores análisis estadísticos, tanto para la totalidad de la población como para la desagregación por sexo, exponemos los errores de muestreo de nuestro estudio (Tabla 1).

La muestra original se compone de 1.200 individuos elegidos aleatoriamente, que puede descomponerse en dos submuestras según sexo, resultando 594 hombres encuestados 
y 626 mujeres, lo que supone, para niveles de confianza del $95 \%{ }^{4}$ y proporciones $p=q=0,5^{5}$, unos errores de muestreo que se expresan en la tabla 1.

Tabla 1. Errores de muestreo.

\begin{tabular}{||l|l|l|l|}
\hline Error muestral & Total & Hombres & Mujeres \\
\hline \hline Andalucía & $2,83 \%$ & $4,02 \%$ & $3,92 \%$ \\
\hline
\end{tabular}

Fuente: Elaboración propia a partir de los datos obtenidos de la ERSA.

\section{RESULTADOS}

A partir de las respuestas que la ciudadanía andaluza ha dado a las preguntas que hemos considerado de interés para el estudio que aquí se presenta, realizamos por separado el análisis de algunas de las cuestiones más relevantes, separándolas en los siguientes subepígrafes.

\subsection{PREDISPOSICIÓN TEÓRICA AL MANTENIMIENTO DEL MEDIOAMBIENTE}

Con el objeto de monetizar la conciencia y preocupación que la población andaluza muestra por el medioambiente vamos a utilizar las respuestas al ítem P2006: "Le voy a mencionar diversos capítulos de gasto público. Dígame, por favor, si a Ud. le gustaría que se gastara más o menos en cada uno de ellos", en el que ofrece a las personas encuestadas que elija entre una de las cinco categorías: "gastar mucho más", "gastar más", "gastar lo mismo que ahora", "gastar menos" y "gastar mucho menos", ordenadas del 1 al 5 respectivamente. El análisis descriptivo de las respuestas nos permitirá situar al medioambiente frente a otras partidas del gasto público.

Por tanto, vamos a utilizar las respuestas relativas al gasto público en medioambiente como predisposición teórica. Las respuestas se han agrupado en "gastar más" (categorías 1 y 2) y "gastar menos" (categorías 4 y 5). En los gráficos 1 y 2 se presentan las respuestas que han quedado agrupadas en la categoría "gastar más", según el tipo de Gasto Público y según el sexo de quienes responden.

\footnotetext{
${ }^{4}$ El umbral para rechazar la hipótesis nula de igualdad de medias (es decir, que las variables no son independientes) es el $5 \%$ (nivel de significación $\alpha=0,05$ ). Todo $p$-valor o valor de probabilidad por debajo de 0,05 indica que se rechaza la hipótesis nula del contraste.

${ }^{5}$ Son las probabilidades de éxito $(p)$ y fracaso $(q=1-p)$ en un experimento de Bernoulli. Como la varianza es igual al producto de ambas $(p \cdot q)$, y dichas probabilidades, obviamente, solo pueden tomar valores en el intervalo [0,1], la varianza toma el valor máximo (que sería el caso más desfavorable) cuando ambas probabilidades toman el valor 0,5 , en cuyo caso $p \cdot q=0,25$. Al tomar el caso más desfavorable (máxima varianza), en caso de ser ésta menor no tendríamos inconveniente, al contrario, ya que nos hemos situado en el peor caso posible.
}

Revista de Estudios Andaluces, vol. 34, núm. 1 (2017) pp. 1-25. e-ISSN: 2340-2776

http://dx.doi.org/10.12795/rea.2017.i34.01

\section{(c) (1) $\Theta$}

SinObraDerivada 4.0 Internacional 
Gráfico 1. Respuestas favorables a "gastar más" por categoría de Gasto Público (en porcentajes). Hombres.

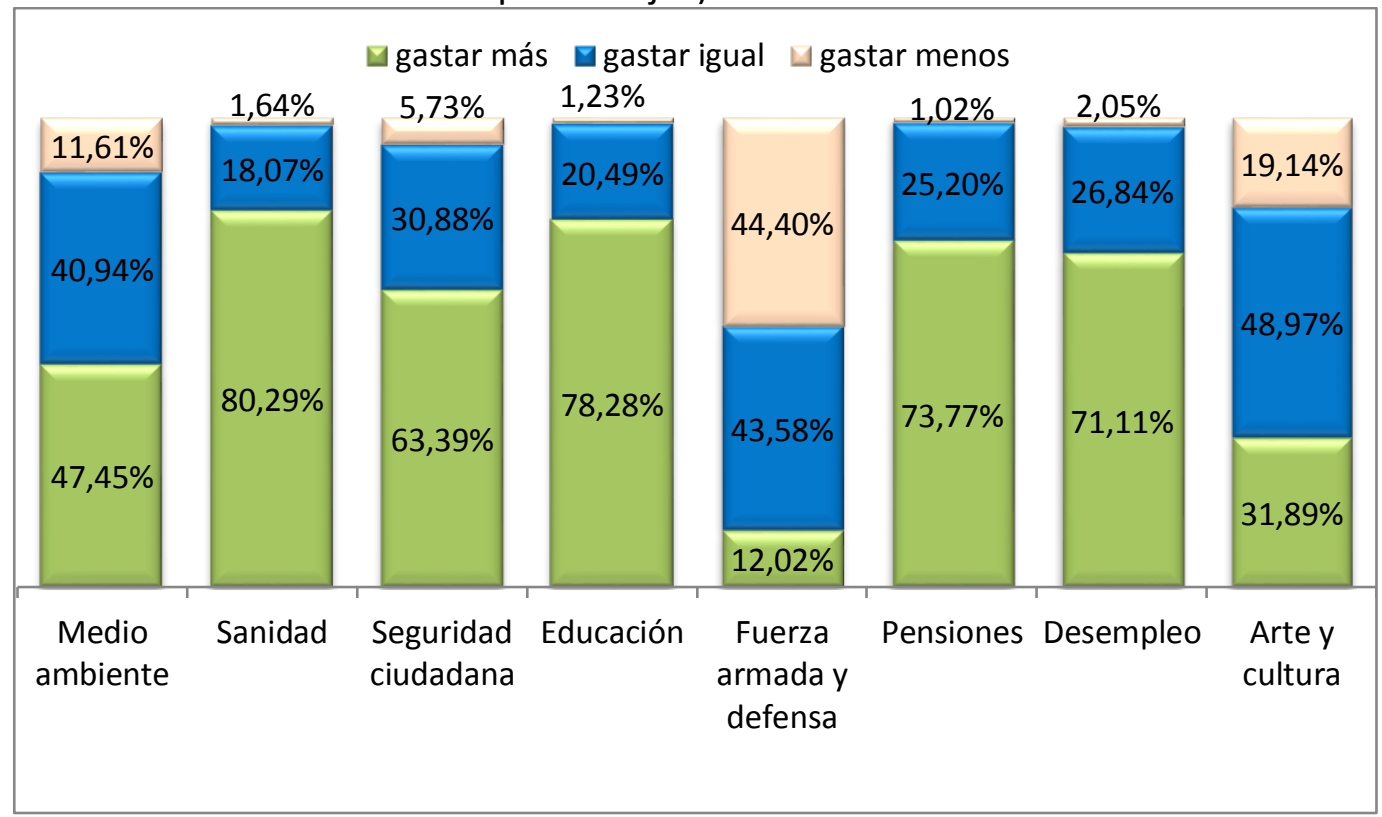

Fuente: Elaboración propia a partir de los datos ERSA.

Gráfico 2. Respuestas favorables a "gastar más" por categoría de Gasto Público (en porcentajes). Mujeres.

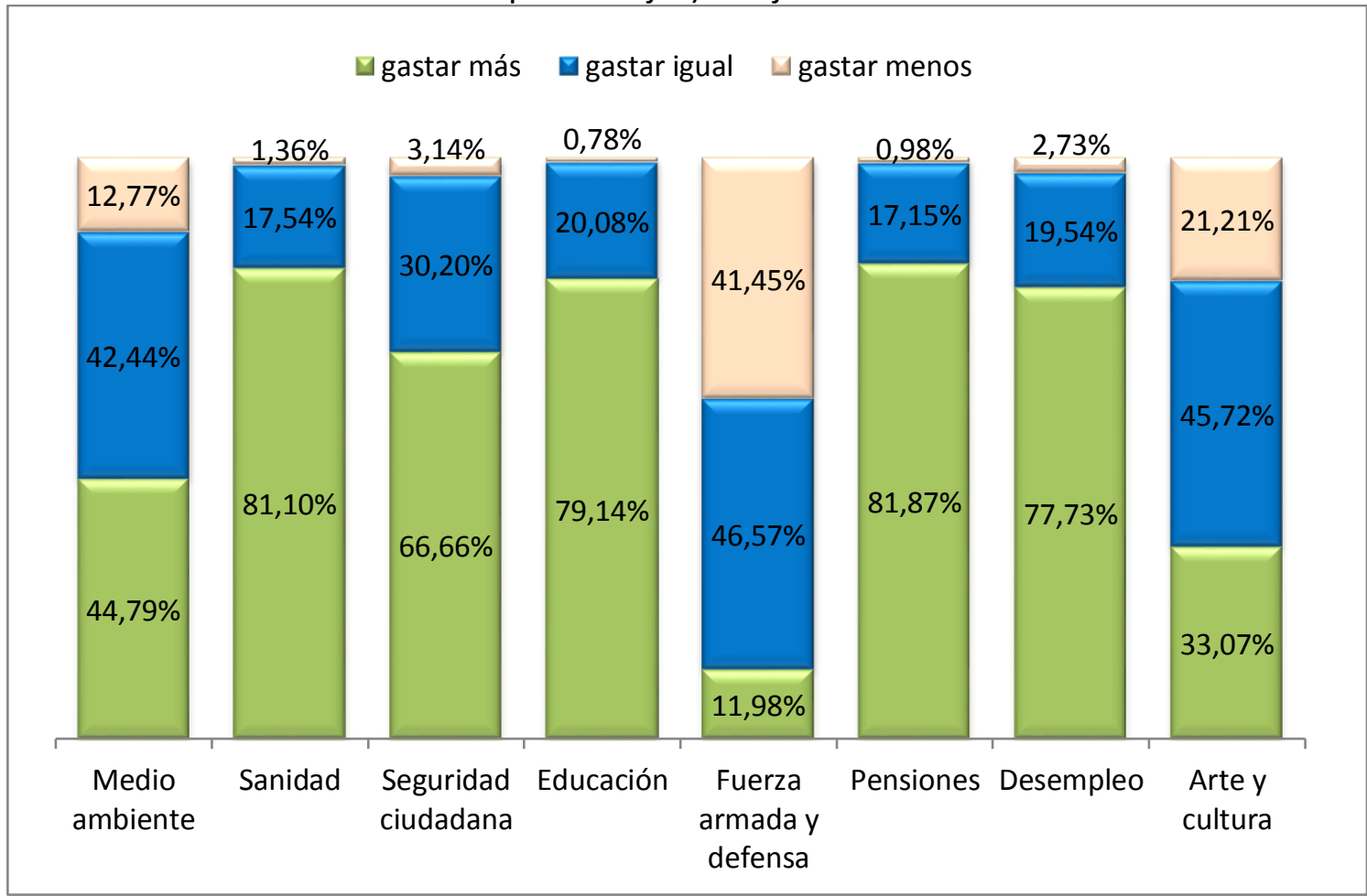

Fuente: Elaboración propia a partir de los datos ERSA.

Revista de Estudios Andaluces, vol. 34, núm. 1 (2017) pp. 1-25. e-ISSN: 2340-2776 http://dx.doi.org/10.12795/rea.2017.i34.01

\section{(c) (i) (3)}


Como se observa en ambos gráficos, el $47,45 \%$ de los hombres y el $44,79 \%$ de las mujeres consideran que el gasto público en la protección del medioambiente debe ser superior y sólo el $11,6 \%$ y el $12,77 \%$ de hombres y mujeres respectivamente, piensan que debería gastarse menos. Si consideramos que esta variable mide los valores (precios públicos) que asignamos a los bienes públicos referenciados, nos encontramos con que el medioambiente ocupa, tanto para hombres como para mujeres, el sexto lugar, sólo por encima del gasto público en arte y cultura y en defensa y fuerzas armadas. Esto confirma los resultados que apuntan los datos de la EBA sobre la importancia del medioambiente frente a otros problemas que, a raíz de la crisis económica, se han convertido en prioritarios para la población en estudio.

Para comprobar si se detectan diferencias significativas entre los sexos se ha utilizado el contraste no paramétrico, $U$ de Mann-Whitney, para el que se ha obtenido un valor $p=0,319$ claramente superior al valor de $\alpha=0,05$, por lo que se puede concluir con un 95\% de confianza que no existen diferencias significativas entre las respuestas a la pregunta sobre si le gustaría que se gastara más o menos en la protección del medioambiente según el sexo de quienes responden.

\subsection{PREDISPOSICIÓN PRÁCTICA AL MANTENIMIENTO DEL MEDIOAMBIENTE}

Una vez se ha establecido lo que la población piensa que debe aumentar el gasto público en la protección del medioambiente, nos preguntamos a continuación si está, de igual forma, dispuesta a asumir este gasto público, en caso en que recayera en la ciudadanía en forma de pagos directos (aumento de precios) o aumento de impuestos. Presentamos, pues los resultados obtenidos respecto a los dos ítems mencionados anteriormente en la metodología (3002.a) y 3002.b)).

Con respecto a la predisposición a pagar precios más elevados para proteger el medioambiente (ítem 3002.a)), en los gráficos 3 y 4 se presentan los porcentajes a cada opción para hombres y mujeres separadamente.

Se observa que el $40,8 \%$ de los hombres no está dispuesto a pagar más (niveles 4 y 5 ) a nivel personal para proteger el medioambiente, porcentaje que se eleva al 43,2\% para las mujeres. Este resultado, en principio, se contradice a nivel monetario con los argumentos teóricos acerca de que la mujer está más predispuesta a asumir conductas proambientales, llegando a la misma conclusión que el estudio que se citó anteriormente de Mostafa, M. (2007). Puede ser que la mujer en general esté dispuesta a asumir dichas conductas siempre y cuando no le supongan precios más elevados. En cualquier caso, se requeriría un análisis más detallado para poder indagar en las causas y motivaciones de estas respuestas.

Revista de Estudios Andaluces, vol. 34, núm. 1 (2017) pp. 1-25. e-ISSN: 2340-2776 http://dx.doi.org/10.12795/rea.2017.i34.01

\section{(c) (i) (3)}

SinObraDerivada 4.0 Internacional 
Gráfico 3. Disposición al pago individual (precios más elevados). Hombres.

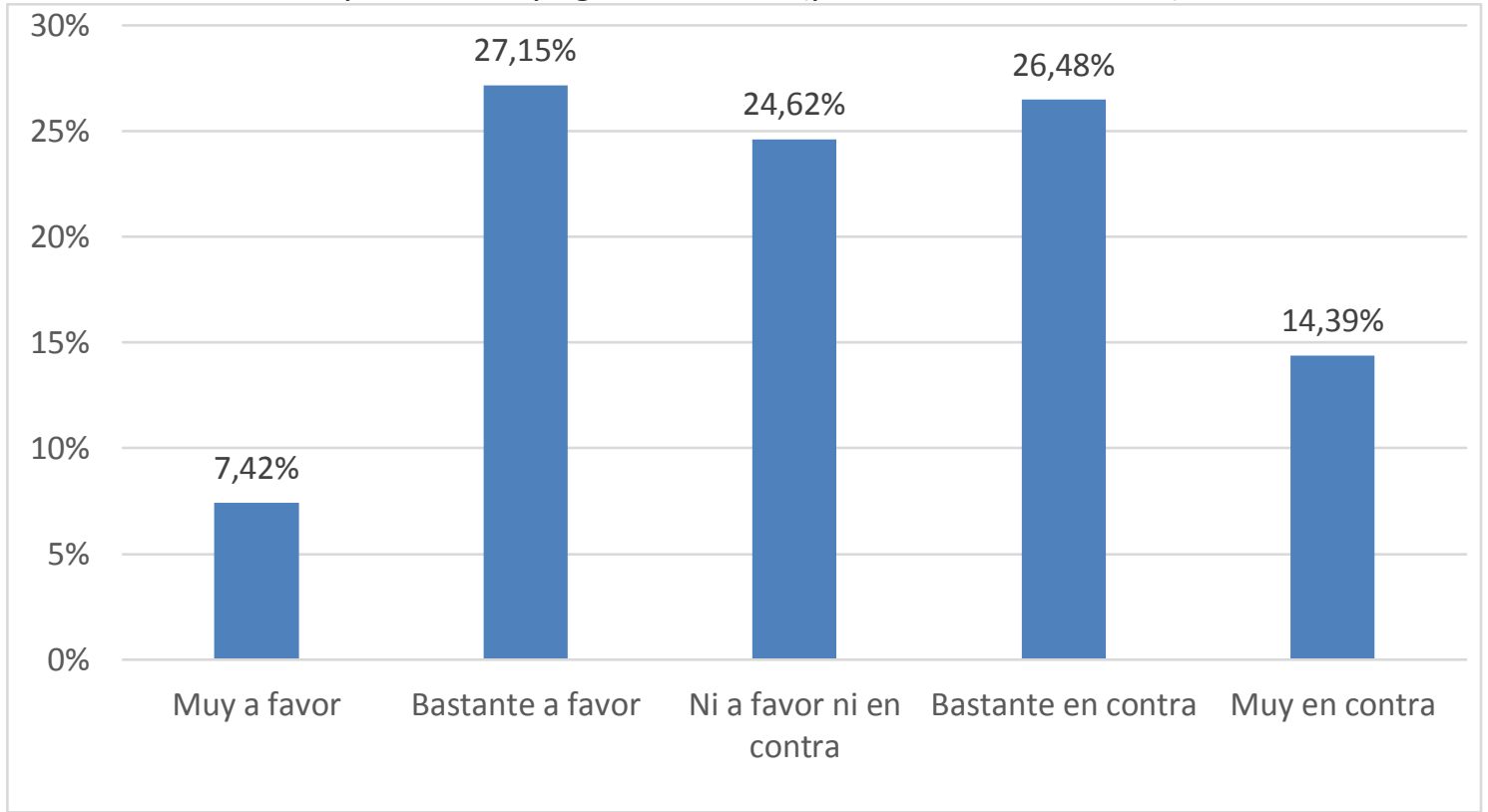

Fuente: Elaboración propia a partir de los datos obtenidos de la ERSA.

Gráfico 4. Disposición al pago individual (precios más elevados). Mujeres.

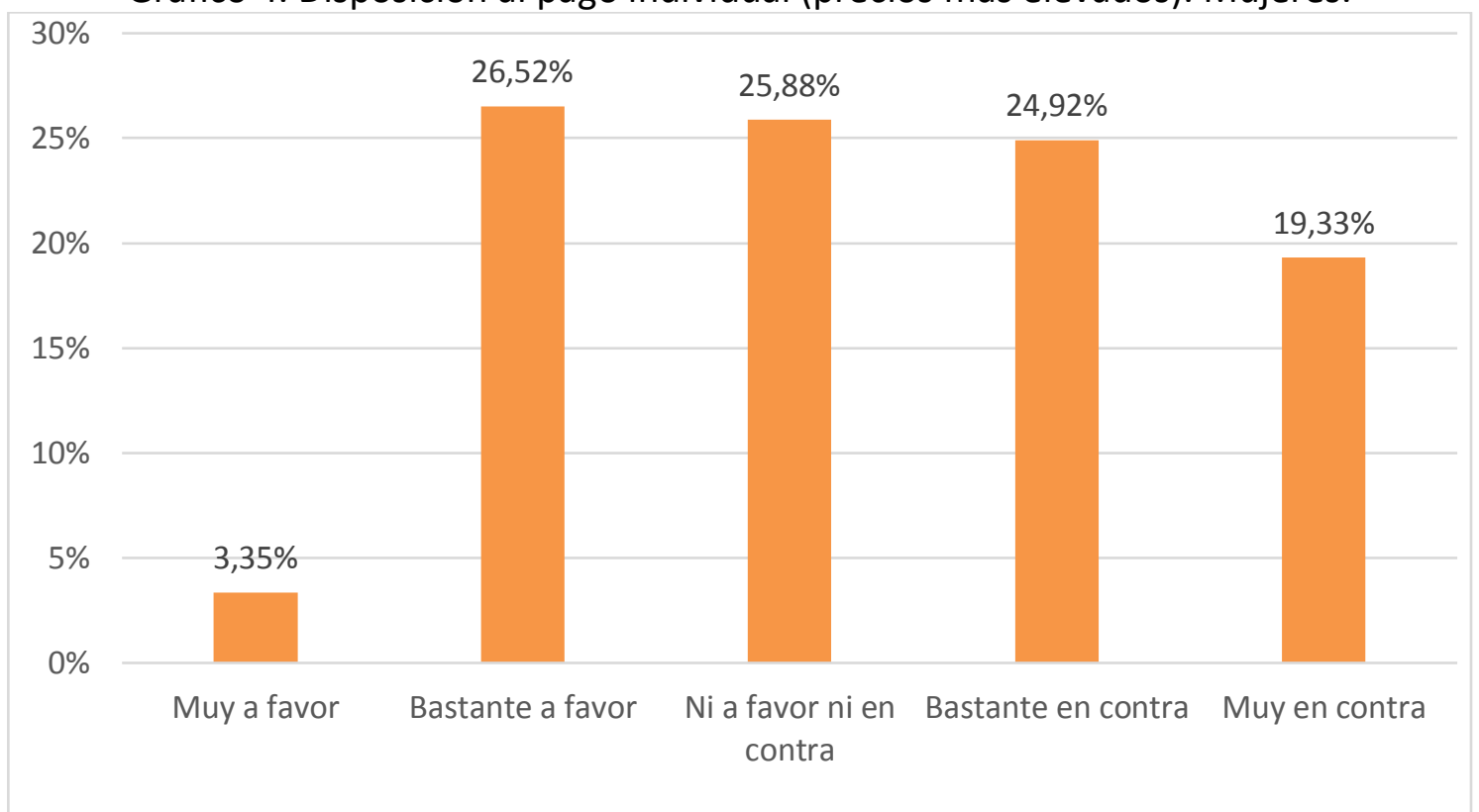

Fuente: Elaboración propia a partir de los datos obtenidos de la ERSA.

Revista de Estudios Andaluces, vol. 34, núm. 1 (2017) pp. 1-25. e-ISSN: 2340-2776 http://dx.doi.org/10.12795/rea.2017.i34.01

\section{(c) (i) $(9)$}


La visualización de los gráficos pone de manifiesto que parece intuirse un comportamiento diferencial entre hombres y mujeres, hecho que contrastamos estadísticamente a través de un contraste de igualdad de medias, en el que resultan diferencias significativas al nivel del $0,6 \%\left(X^{2}=14,46\right)$, con un intervalo de confianza para la igualdad de medias al $95 \%$ de $(-0,303 ;-0,041)$, concluyendo que la disposición al pago de los hombres es significativamente superior a la de las mujeres. En este aspecto habría que tener también en cuenta el poder adquisitivo de hombres y mujeres ${ }^{6}$, que puede condicionar significativamente la disposición al pago. Es decir, si más mujeres que hombres tienen contratos peor remunerados, o muchas de ellas no cuentan con ingresos propios, es lógico pensar que su disposición a pagar se vea influenciada por este hecho.

Ahora bien, quizás lo más relevante, y por ello es necesario destacar, es la opinión al respecto de quienes declaraban que deseaban mayor gasto público en protección al medioambiente. De entre estas personas, el $49,6 \%$ de los hombres se muestran dispuestos a pagar precios más altos, mientras solo el $45,9 \%$ de las mujeres están dispuestas a ello. Además, existe una correlación pequeña, en torno al 35\%, entre la elección de mayor gasto público en medioambiente y pagar precios más elevados para la protección del mismo, tanto para hombres como para mujeres. Por tanto, parece que es mayor la propensión favorable hacia una mayor dedicación de recursos públicos hacia la protección medioambiental vía gasto público, que la predisposición a pagar directamente por ello a través del pago de precios más elevados. Una cuestión que puede estar relacionada con este hecho es que falta una conciencia general sobre la cuestión de que el gasto público realmente es un gasto de todos y cada uno de nosotros como contribuyentes y como receptores de los servicios públicos. Gran parte de la ciudadanía solo percibe como gasto el que realiza directamente de su bolsillo. Sería interesante indagar algo más en esta cuestión, a través de entrevistas en profundidad, análisis de caso, etc.

Por otro lado, con respecto a la predisposición a pagar más impuestos (ítem 3002.b)) que se presenta a las personas encuestadas en la misma forma que el ítem 3002.a), se observa en los gráficos 5 y 6 (para hombres y mujeres respectivamente) que ambos sexos están predominantemente dispuestos a no pagar más impuestos para proteger el medioambiente, no existiendo entre las opiniones diferencias significativas al $5 \%$ salvo en las posiciones extremas: "muy a favor" y "muy en contra". Lo anterior se traduce en una diferencia significativa entre las medianas de ambas muestras (Prueba de KruskalWallis $^{7} p=0,0225819$ ).

\footnotetext{
${ }^{6}$ Entre otros motivos, dada la brecha salarial de género que muestra que los hombres siguen ganando más que las mujeres.

${ }^{7}$ Con esta prueba se realiza el contraste para comprobar si se puede afirmar que existen diferencias significativas entre los sexos. En este caso, dado que las variables están medidas en una escala de Likert, es más correcto hacer la comparación entre las medianas (en lugar de utilizar las medias).
}

Revista de Estudios Andaluces, vol. 34, núm. 1 (2017) pp. 1-25. e-ISSN: 2340-2776 http://dx.doi.org/10.12795/rea.2017.i34.01 (c) (1) (9) SinObraDerivada 4.0 Internacional 
Gráfico 5. Disposición a Pagar más impuestos para proteger el medioambiente. Hombres.

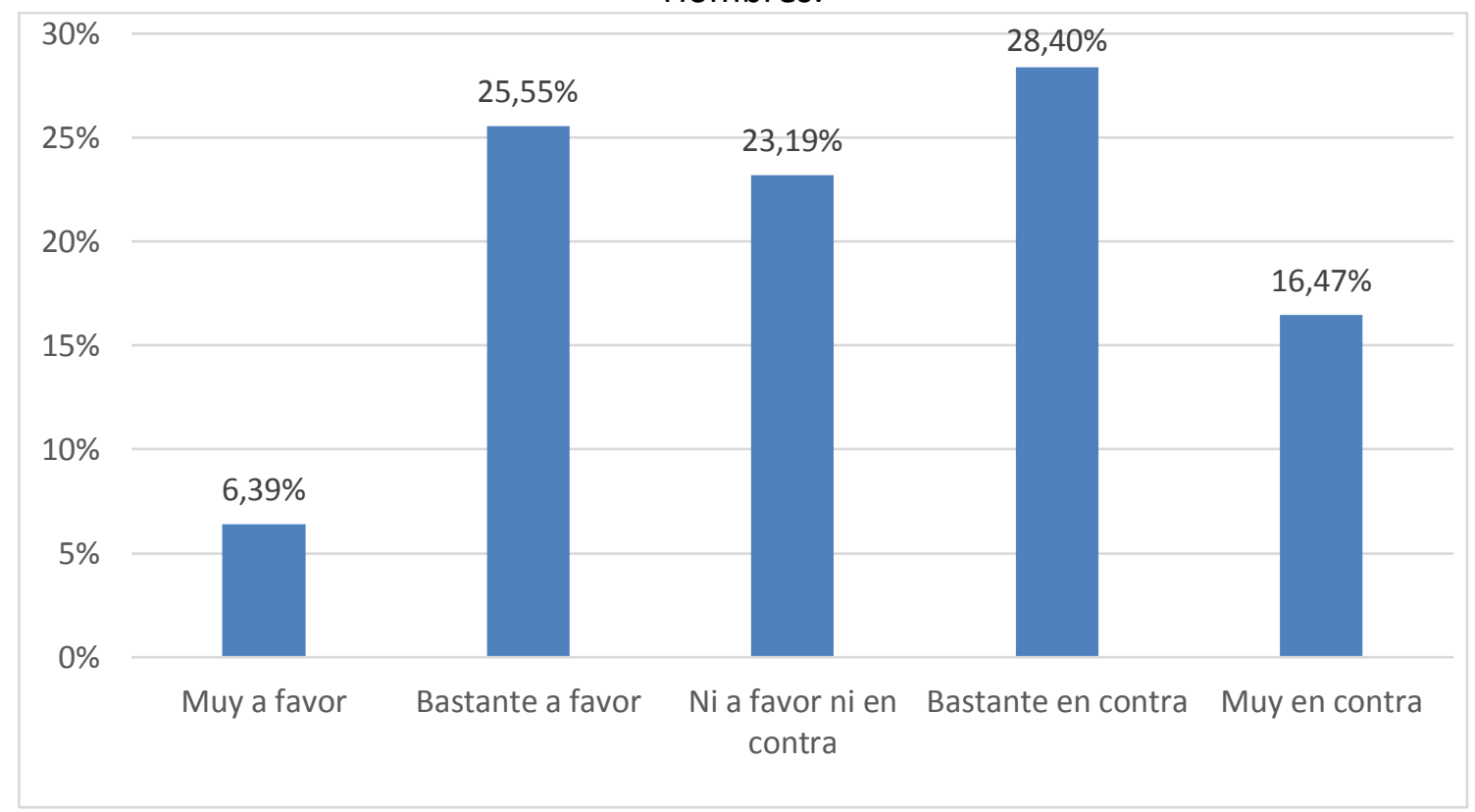

Fuente: Elaboración propia a partir de los datos obtenidos de la ERSA.

Gráfico 6. Disposición a Pagar más impuestos para proteger el medioambiente. Mujeres.

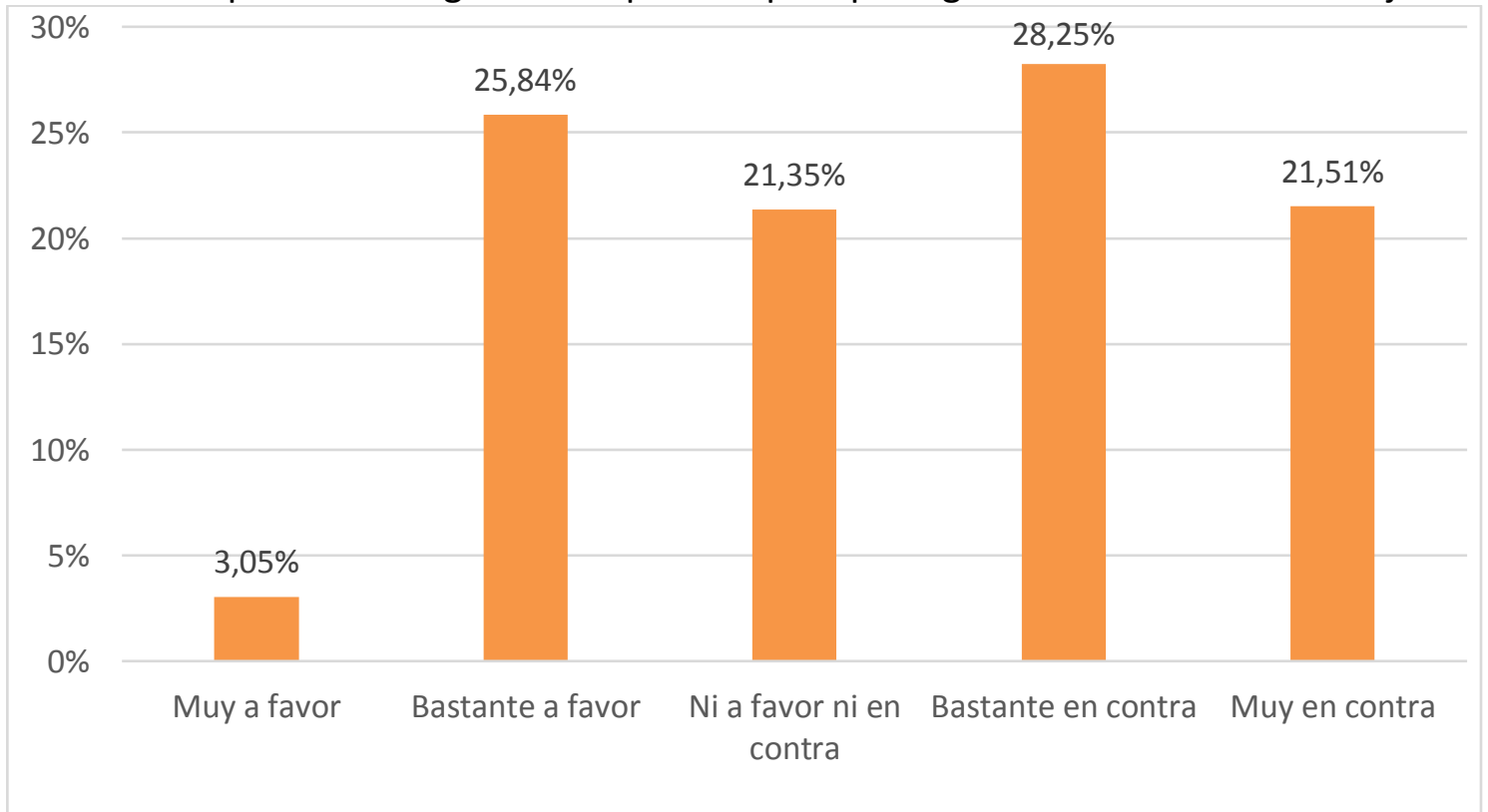

Fuente: Elaboración propia a partir de los datos obtenidos de la ERSA

Revista de Estudios Andaluces, vol. 34, núm. 1 (2017) pp. 1-25. e-ISSN: 2340-2776 http://dx.doi.org/10.12795/rea.2017.i34.01 (c) (i) (3) SinObraDerivada 4.0 Internacional 
Se observa que el $44,87 \%$ de los hombres no está dispuesto a pagar más impuestos (niveles 4 y 5), cifra que se eleva al $49,76 \%$ para las mujeres. Volvemos, pues a encontrarnos con resultados distintos a los postulados teóricos que indicaban una mayor sensibilidad y concienciación medioambiental en las mujeres que en los hombres. $\mathrm{Y}$, de nuevo, no existe una correlación importante (en torno al 40\%), ni para hombres ni para mujeres, entre la opción de mayor gasto público en medioambiente y la disposición a pagar más impuestos para ello.

Con los resultados obtenidos hasta el momento aceptamos la hipótesis primera sobre la existencia de una brecha entre la preocupación que el individuo declara por el medioambiente y la disposición que tiene a contribuir monetariamente al mantenimiento del mismo, ya sea a través de pagar precios más elevados o vía aumento de impuestos.

\subsection{POSIBLES DIFERENCIAS DE GÉNERO EN LA CONCIENCIACIÓN MEDIOAMBIENTAL}

Además de la posible brecha existente entre la preocupación por el medioambiente y la traducción de dicha preocupación en una predisposición positiva a contribuir en la protección medioambiental a través de la aportación individual, sea vía pago de precios más elevados o pago de impuestos, habíamos planteado una segunda hipótesis relativa al comportamiento diferencial por género ${ }^{8}$. En este sentido hemos encontrado resultados contradictorios. Si utilizamos el indicador relativo a precios más elevados, parece que sí existe este comportamiento diferencial; sin embargo, si medimos la brecha a través del indicador de pago de impuestos, encontramos que no existen diferencias significativas entre ellos. Este resultado nos lleva a examinar con mayor atención las relaciones entre las intenciones declaradas para ambas opciones.

En las tablas 2 y 3 comparamos ambas opciones (la predisposición teórica a gastar más para proteger el medioambiente, con las dos alternativas que se les han ofrecido: pagar precios más elevados y pagar más impuestos) separando para hombres y mujeres. Para ambos sexos existe una correlación a un nivel superior al $80 \%$ entre las respuestas a los dos ítems. Ahora bien, si nos restringimos a aquellos que manifiestan un interés por gastar más o mucho más en la protección del medioambiente (categorías 1 y 2), los gráficos 7 y 8 nos permiten visualizar las diferencias. En el eje horizontal está la disposición a pagar precios más elevados y en el vertical la de pagar más impuestos.

La lógica nos dicta que quienes opten por determinada opción respecto al pago de precios, se decantarán mayoritariamente por la misma opción en lo referente al pago de impuestos. Esto, se verifica claramente para las mujeres en la opción 1, donde las

\footnotetext{
${ }^{8}$ Nos referimos a un comportamiento distinto de hombres y mujeres debido a las diferencias de género que aún persisten en nuestra sociedad, más allá de las diferencias biológicas o por sexo.

Revista de Estudios Andaluces, vol. 34, núm. 1 (2017) pp. 1-25. e-ISSN: 2340-2776 http://dx.doi.org/10.12795/rea.2017.i34.01 (c) (1)(9) SinObraDerivada 4.0 Internacional
} 
Tabla 2. Relaciones entre los indicadores utilizados. Hombres.

\begin{tabular}{|c|c|c|c|c|c|c|c|c|c|c|c|c|}
\hline \multirow{2}{*}{\multicolumn{2}{|c|}{ Hombres }} & & \multicolumn{5}{|c|}{ precios más elevados } & \multicolumn{5}{|c|}{ más impuestos } \\
\hline & & & 1 & 2 & 3 & 4 & 5 & 1 & 2 & 3 & 4 & 5 \\
\hline \multirow{5}{*}{ 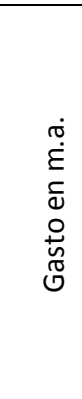 } & 1 & $\begin{array}{l}\text { Valor absoluto } \\
\% \text { de gasto en ma }\end{array}$ & $\begin{array}{l}6 \\
11,8 \%\end{array}$ & $\begin{array}{l}3 \\
5,9 \%\end{array}$ & $\begin{array}{l}3 \\
5,9 \%\end{array}$ & $\begin{array}{l}18 \\
35,3 \%\end{array}$ & $\begin{array}{l}21 \\
41,2 \%\end{array}$ & $\begin{array}{l}20 \\
39,2 \%\end{array}$ & $\begin{array}{l}20 \\
39,2 \%\end{array}$ & $\begin{array}{l}5 \\
9,8 \%\end{array}$ & $\begin{array}{l}4 \\
7,8 \%\end{array}$ & $\begin{array}{l}2 \\
3,9 \%\end{array}$ \\
\hline & 2 & $\begin{array}{l}\text { Valor absoluto } \\
\% \text { de gasto en ma }\end{array}$ & $\begin{array}{l}9 \\
4,0 \% \\
\end{array}$ & $\begin{array}{l}34 \\
15,0 \%\end{array}$ & $\begin{array}{l}25 \\
11,0 \%\end{array}$ & $\begin{array}{l}101 \\
44,5 \%\end{array}$ & $\begin{array}{l}58 \\
25,6 \%\end{array}$ & $\begin{array}{l}29 \\
12,8 \%\end{array}$ & $\begin{array}{l}130 \\
57,3 \%\end{array}$ & $\begin{array}{l}44 \\
19,4 \%\end{array}$ & $\begin{array}{l}20 \\
8,8 \%\end{array}$ & $\begin{array}{l}4 \\
1,8 \% \\
\end{array}$ \\
\hline & 3 & $\begin{array}{l}\text { Valor absoluto } \\
\% \text { de gasto en ma }\end{array}$ & $\begin{array}{ll}13 \\
5,4 \% \\
\end{array}$ & $\begin{array}{l}50 \\
20,9 \% \\
\end{array}$ & $\begin{array}{l}34 \\
14,2 \% \\
\end{array}$ & $\begin{array}{l}89 \\
37,2 \% \\
\end{array}$ & $\begin{array}{l}53 \\
22,2 \% \\
\end{array}$ & $\begin{array}{l}25 \\
10,5 \% \\
\end{array}$ & $\begin{array}{l}103 \\
43,1 \% \\
\end{array}$ & $\begin{array}{l}66 \\
27,6 \% \\
\end{array}$ & $\begin{array}{l}37 \\
15,5 \% \\
\end{array}$ & $\begin{array}{l}8 \\
3,3 \% \\
\end{array}$ \\
\hline & 4 & $\begin{array}{l}\text { Valor absoluto } \\
\% \text { de gasto en ma }\end{array}$ & $\begin{array}{l}5 \\
8,6 \% \\
\end{array}$ & $\begin{array}{l}13 \\
22,4 \% \\
\end{array}$ & $\begin{array}{l}15 \\
25,9 \% \\
\end{array}$ & $\begin{array}{l}14 \\
24,1 \% \\
\end{array}$ & $\begin{array}{l}11 \\
19,0 \% \\
\end{array}$ & $\begin{array}{ll}2 \\
3,4 \% \\
\end{array}$ & $\begin{array}{l}23 \\
39,7 \% \\
\end{array}$ & $\begin{array}{l}7 \\
12,1 \% \\
\end{array}$ & $\begin{array}{l}18 \\
31,0 \% \\
\end{array}$ & $\begin{array}{l}8 \\
13,8 \% \\
\end{array}$ \\
\hline & 5 & $\begin{array}{l}\text { Valor absoluto } \\
\% \text { de gasto en ma }\end{array}$ & $\begin{array}{l}1 \\
10,0 \%\end{array}$ & $\begin{array}{l}1 \\
10,0 \%\end{array}$ & $\begin{array}{ll}0 \\
0,0 \% \\
\end{array}$ & $\begin{array}{l}4 \\
40,0 \% \\
\end{array}$ & $\begin{array}{l}4 \\
40,0 \% \\
\end{array}$ & $\begin{array}{l}2 \\
20,0 \% \\
\end{array}$ & $\begin{array}{l}0 \\
0,0 \% \\
\end{array}$ & $\begin{array}{l}3 \\
30,0 \% \\
\end{array}$ & $\begin{array}{l}4 \\
40,0 \% \\
\end{array}$ & $\begin{array}{l}1 \\
10,0 \% \\
\end{array}$ \\
\hline
\end{tabular}

Nota: En horizontal (Gasto en m.a.): 1"gastar mucho más", 2"gastar más",3 "gastar lo mismo que ahora”, 4"gastar menos" y 5"gastar mucho menos"

En vertical (precios o impuestos): 1 "Muy a favor", 2 "Bastante a favor", 3 "Ni a favor ni en contra”, 4 "Bastante en contra” y 5 "Muy en contra" Fuente: Elaboración propia a partir de los datos obtenidos de la ERSA.

Tabla 3. Relaciones entre los indicadores utilizados. Mujeres.

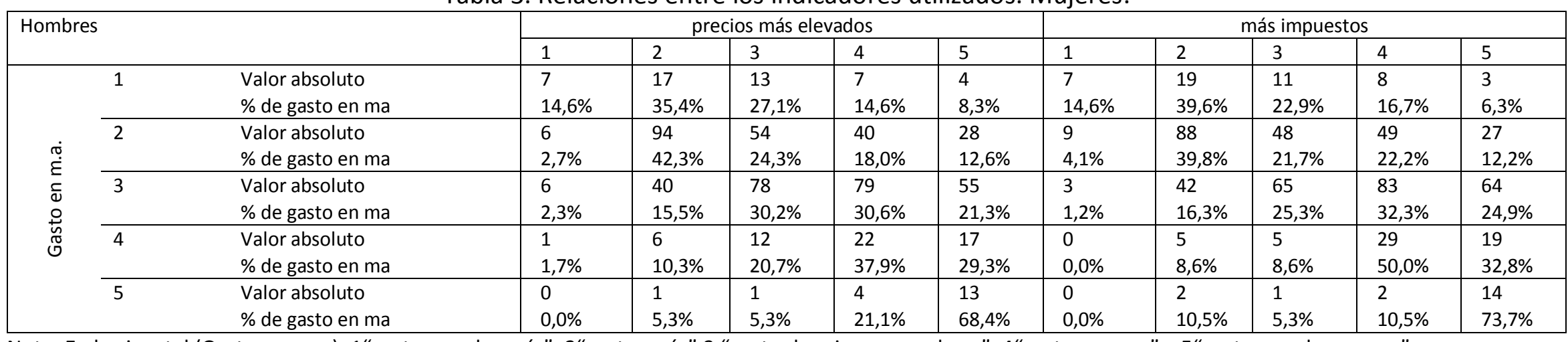

Nota: En horizontal (Gasto en m.a.): 1"gastar mucho más", 2"gastar más",3 "gastar lo mismo que ahora”, 4"gastar menos" y 5"gastar mucho menos"

En vertical (precios o impuestos): 1 "Muy a favor", 2 "Bastante a favor", 3 "Ni a favor ni en contra", 4 "Bastante en contra" y 5 "Muy en contra"

Fuente: Elaboración propia a partir de los datos obtenidos de la ERSA.

Revista de Estudios Andaluces, vol. 34, núm. 1 (2017) pp. 1-25. e-ISSN: 2340-2776

http://dx.doi.org/10.12795/rea.2017.i34.01

(C) $\oplus \Theta \Theta$

Esta obra se distribuye con la licencia Creative Commons Reconocimiento-NoComercial-SinObraDerivada 4.0 Internacional 
Gráfico 7: Relación entre disposición al pago-precios y disposición al pago-impuestos. Hombres.

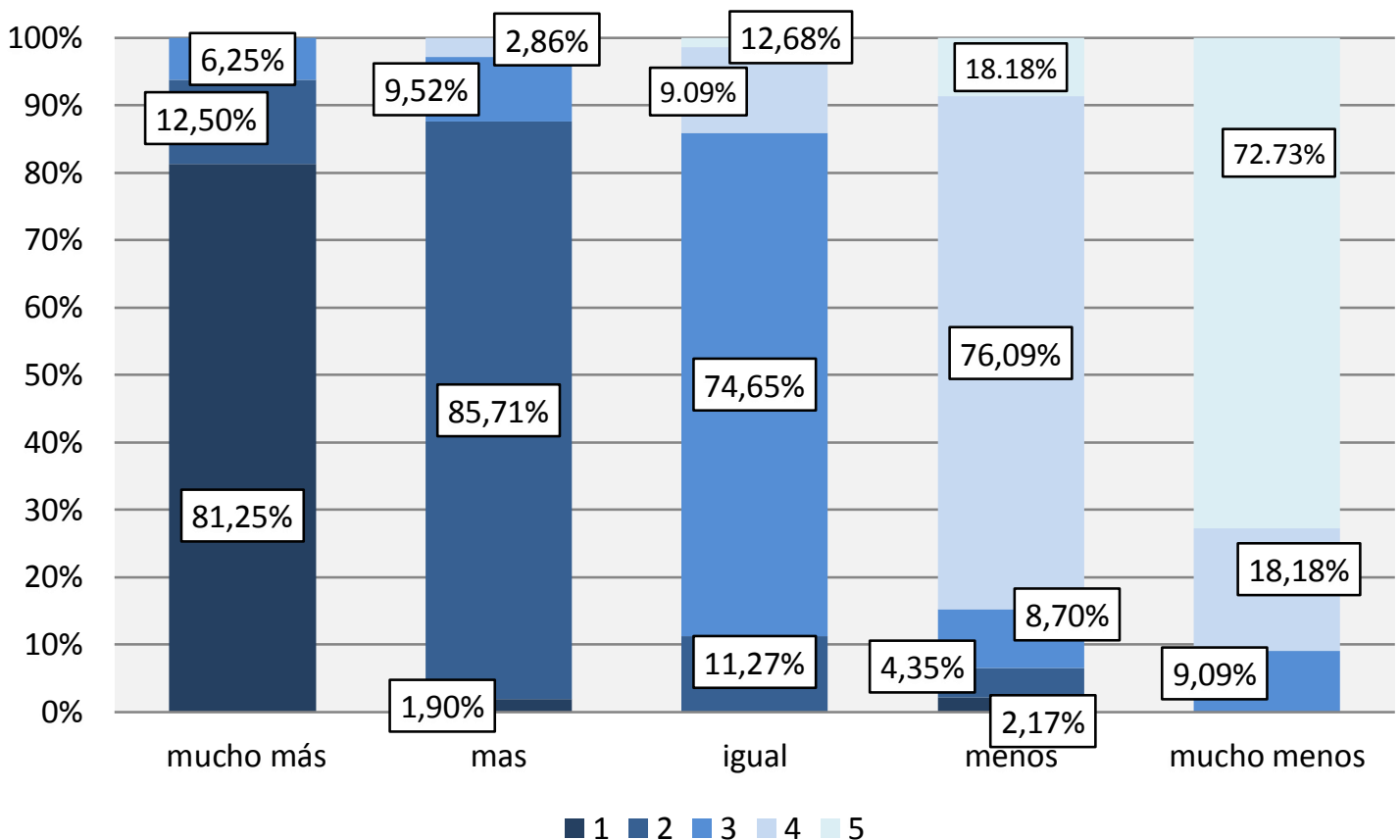

1"mucho más impuestos", 2"más impuestos",3 "los mismos impestos que ahora", 4"menos impuestos" y 5 "mucho menos impuestos"

Fuente: Elaboración propia a partir de los datos obtenidos de la ERSA.

Gráfico 8: Relación entre disposición al pago-precios y disposición al pago-impuestos.

Mujeres.

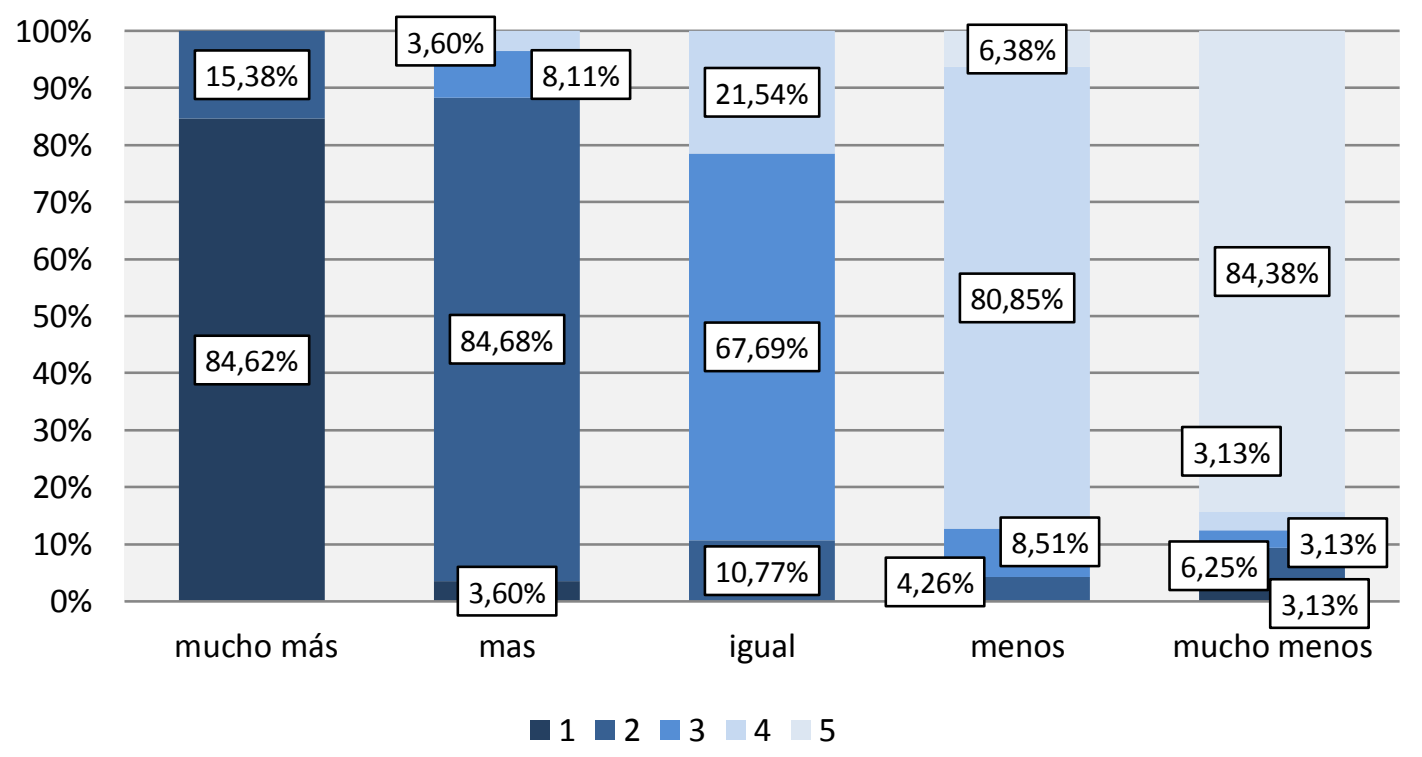

1"mucho más impuestos", 2"más impuestos",3 "Ios mismos impestos que ahora", 4"menos impuestos" y 5 "mucho menos impuestos"

Fuente: Elaboración propia a partir de los datos obtenidos de la ERSA.

Revista de Estudios Andaluces, vol. 34, núm. 1 (2017) pp. 1-25. e-ISSN: 2340-2776 http://dx.doi.org/10.12795/rea.2017.i34.01

(c) $($ †) $\ominus$

cC. Esta obra se distribuye con la licencia Creative Commons Reconocimiento-NoComercialSinObraDerivada 4.0 Internacional 
que están dispuestas a pagar precios mucho más elevados se muestran dispuestas a pagar mucho más o más impuestos. En esta misma opción, para los hombres, aunque también hay mayor porcentaje de dispuestos a pagar mucho más o más, pero un $6,25 \%$ se muestran indiferentes a la cuestión de impuestos.

En la otra opción extrema, "pagar mucho menos", los hombres se comportan de manera esperada con respecto a pagar también menos impuestos, y el 9,09\% se muestran indiferentes en el tema de impuestos. Para las mujeres dentro de esta opción de precios, la diversidad respecto al pago de impuestos es mayor, incluso un 6,25\% está dispuesta a pagar más impuestos y un 3,13\% mucho más. En el resto de las opciones, en términos generales, encontramos mayor diversidad en los hombres que en las mujeres.

Es posible que estas personas que están pensando que es realmente necesario que aumente el gasto público en la protección del medioambiente, y que debe ser la Administración Pública la que asuma en gran medida esa responsabilidad, dedicando una partida superior del gasto público a esta cuestión, al mismo tiempo no estén de acuerdo con la gestión que se realiza de sus impuestos, por lo que no son favorables a que se les aumenten, independientemente de la predisposición al pago que declaren. Las diferencias encontradas nos dan pie a cuestionarnos qué variables de las más utilizadas por la literatura (sus ingresos, las percepciones sobre el deterioro medioambiental y sobre la importancia de sus decisiones, la ideología política y su confianza en los demás ${ }^{9}$ ) están afectando a las respuestas de hombres y mujeres, con respecto a su disposición al pago (disposición a pagar precios más elevados).

\subsubsection{LOS INGRESOS DE LA UNIDAD FAMILIAR COMO CONDICIONANTES}

Como esperábamos, ambos están condicionados por sus niveles de ingresos (correlaciones significativas y negativas): A menor ingreso menor disposición al pago. Aunque la relación para las mujeres casi duplica a la de los hombres (coeficientes respectivos $-0,270$ y $-0,172$ ).

\subsubsection{PERCEPCIÓN SOBRE EL VERDADERO DETERIORO MEDIOAMBIENTAL}

En primer lugar, la percepción sobre el verdadero deterioro medioambiental puede influir en la disposición al pago (Disposición al Pago individual), en un sentido positivo. Es decir, cuanta mayor sea nuestra percepción del deterioro, mayor será nuestra disposición al pago.

Para corroborar esta afirmación utilizaremos las respuestas al ítem 3001e): "Muchas de las reclamaciones sobre las amenazas al medioambiente son exageradas", en la que se ofrece a la persona encuestada para que elija una de entre cinco opciones: "Muy de

\footnotetext{
9 La base de datos utilizada no permite extraer conclusiones significativas si consideramos otros condicionantes tales como el nivel cultural.
}

Revista de Estudios Andaluces, vol. 34, núm. 1 (2017) pp. 1-25. e-ISSN: 2340-2776 http://dx.doi.org/10.12795/rea.2017.i34.01 c) (1) $(9)$ 
acuerdo", "de acuerdo", "ni de acuerdo ni en desacuerdo", "en desacuerdo" y "muy en desacuerdo", ordenadas de 1 a 5 respectivamente. En este caso y para las variables siguientes se han agrupado los datos procedentes de la disposición a pagar en "muy a favor" y "bastante a favor" en la posición "a favor" y se ha agrupado en la posición "en contra" las dos posiciones siguientes "bastante en contra" y "muy en contra". Obtenemos en el colectivo de hombres que piensan que no está tan deteriorado el medioambiente, que un $60,8 \%$ está en contra de aceptar precios más elevados, por el contrario, entre los que piensan que sí lo está, más de la mitad, un $54,9 \%$, está a favor de un mayor pago. En el colectivo de mujeres los resultados son aún más determinantes. Así los porcentajes respectivos pasan a ser del $71 \%$ y $53,1 \%$.

¿Afecta pues la percepción del deterioro medioambiental a la disposición al pago? Realizados los contrastes oportunos resulta que dicha variable no resulta significativa en los hombres, cuyo pago no viene afectado por la opinión que tenga sobre el deterioro actual del medioambiente $y$, sin embargo, sí lo es en las mujeres $(F=12,69 \alpha<0,01)$ y con el signo esperado, a mayor percepción del deterioro mayor probabilidad de aceptar pagar precios más elevados.

\subsubsection{REPERCUSIÓN DE LOS ACTOS INDIVIDUALES EN LA COLECTIVIDAD}

Por otra parte, la creencia de que nuestros actos individuales tienen mayor o menor repercusión en la colectividad también puede influirnos en el momento de adoptar una decisión. Mediremos esto mediante las respuestas al ítem 3001a): "Simplemente es muy difícil que una persona como yo pueda hacer algo por el medioambiente", en la que se ofrece a la persona encuestada para que elija una de entre cinco opciones: "Muy de acuerdo", "de acuerdo", "ni de acuerdo ni en desacuerdo", "en desacuerdo" y "muy en desacuerdo", ordenadas de 1 a 5 respectivamente.

En el colectivo de hombres que piensan que sus actuaciones no son determinantes, un $40,7 \%$ está en contra de aceptar precios más elevados, frente al $34,4 \%$ que está a favor, $y$, sorprendentemente no llegan a la mitad, un 47,3\%, aquellos que, pensando que individualmente pueden mejorar el medioambiente, están a favor de un mayor pago, estando en contra de pagar más un $33,8 \%$.

En el colectivo de mujeres los resultados son aún más determinantes. Así el 59,2\% de las que piensan que sus actos difícilmente pueden afectar al medioambiente, consecuentemente están en contra de pagar precios más elevados, y de aquellas que piensan que sí pueden colaborar, sólo el $40,2 \%$ está dispuesto a hacerlo. Los porcentajes del grupo que, según nuestra hipótesis de partida son incongruentes, pasan a ser del 18,5 en un extremo y $34,4 \%$ en el otro.

Revista de Estudios Andaluces, vol. 34, núm. 1 (2017) pp. 1-25. e-ISSN: 2340-2776

http://dx.doi.org/10.12795/rea.2017.i34.01

\section{(c) (i) (3)}

SinObraDerivada 4.0 Internacional 
Dados estos porcentajes, nos preguntamos si afecta la percepción de que nuestro acto individual puede hacer algo por el medioambiente influye en la disposición a pagar. Pues bien, realizados los análisis correspondientes, no existe relación para ninguno de los dos colectivos, ni para hombres ni para mujeres, sus disposiciones al pago no están correlacionadas significativamente con la opinión que tienen acerca de la eficacia medioambiental de sus decisiones, tomadas éstas independientemente de que piensen que van a afectar o no a la colectividad (los coeficientes de correlación son muy bajos, 0,102 para hombres y -0,14 para mujeres, y no significativos al 95\%).

\subsubsection{IDEOLOGÍA POLÍTICA}

Otra de las variables manejadas más comúnmente en los estudios medioambientales es la ideología política. Los estudios internacionales precedentes señalan que las posiciones hacia la "izquierda" muestran más actitudes y conductas proambientales que aquellas más inclinadas a la "derecha". Para analizar este hecho entre los andaluces y andaluzas acudimos a la variable denominada "ideología", reflejada en el ítem P6009: "Cuando se habla de política, generalmente se utilizan las expresiones izquierda y derecha ¿Podría decirme ahora en qué lugar se ubicaría usted en una escala de 1 a 10 donde 1 es de izquierdas y 10 de derechas?". Los resultados obtenidos, agrupando en la izquierda a los que se ubican entre 1 y 4 incluidos y en derecha del 7 en adelante, muestran, para los hombres en la izquierda un porcentaje del $41,5 \%$ de los que están a favor de pagar y del $39,8 \%$ de los que están en contra. En la derecha estos porcentajes son del $22,4 \%$ y $51 \%$, es decir, tal como predicen los estudios, pero además con diferencias más acusadas entre los de derechas.

Para las mujeres estos porcentajes son $37,1 \%$ y $42,4 \%$, lo que resulta contrario a lo que sostienen otros estudios, y para la derecha $22,8 \%$ y $43,2 \%$, comportamiento según lo esperado. A la vista de estos resultados nos planteamos si la ideología política es determinante.

Los test Anova's realizados nos confirman que la ideología política no es una variable significativa para las mujeres $(F=0,63 p=0,531)$ y sí lo es para los hombres $(F=2,69$ $p=0,069)$.

\subsubsection{CONFIANZA EN LOS DEMÁS}

Una figura determinante en los estudios sobre la disposición al pago es la del free-rider ("el gorrón"), que es quien se aprovecha del buen comportamiento del resto de los miembros de una colectividad. Si pensamos que esta figura abunda seremos, lógicamente, menos propensos a sacrificarnos.

Esta afirmación vamos a contrastarla en los ciudadanos andaluces a través del ítem P5003: “¿Diría usted que, por lo general, se puede confiar en la mayoría de la gente, o que nunca se es lo bastante prudente en el trato con los demás?", en la que se ofrece a

Revista de Estudios Andaluces, vol. 34, núm. 1 (2017) pp. 1-25. e-ISSN: 2340-2776 http://dx.doi.org/10.12795/rea.2017.i34.01

$$
\text { (c) }(1)(9)
$$


Gráfico 9: Relación entre el grado de confianza en los demás y la disposición al pago en los hombres.

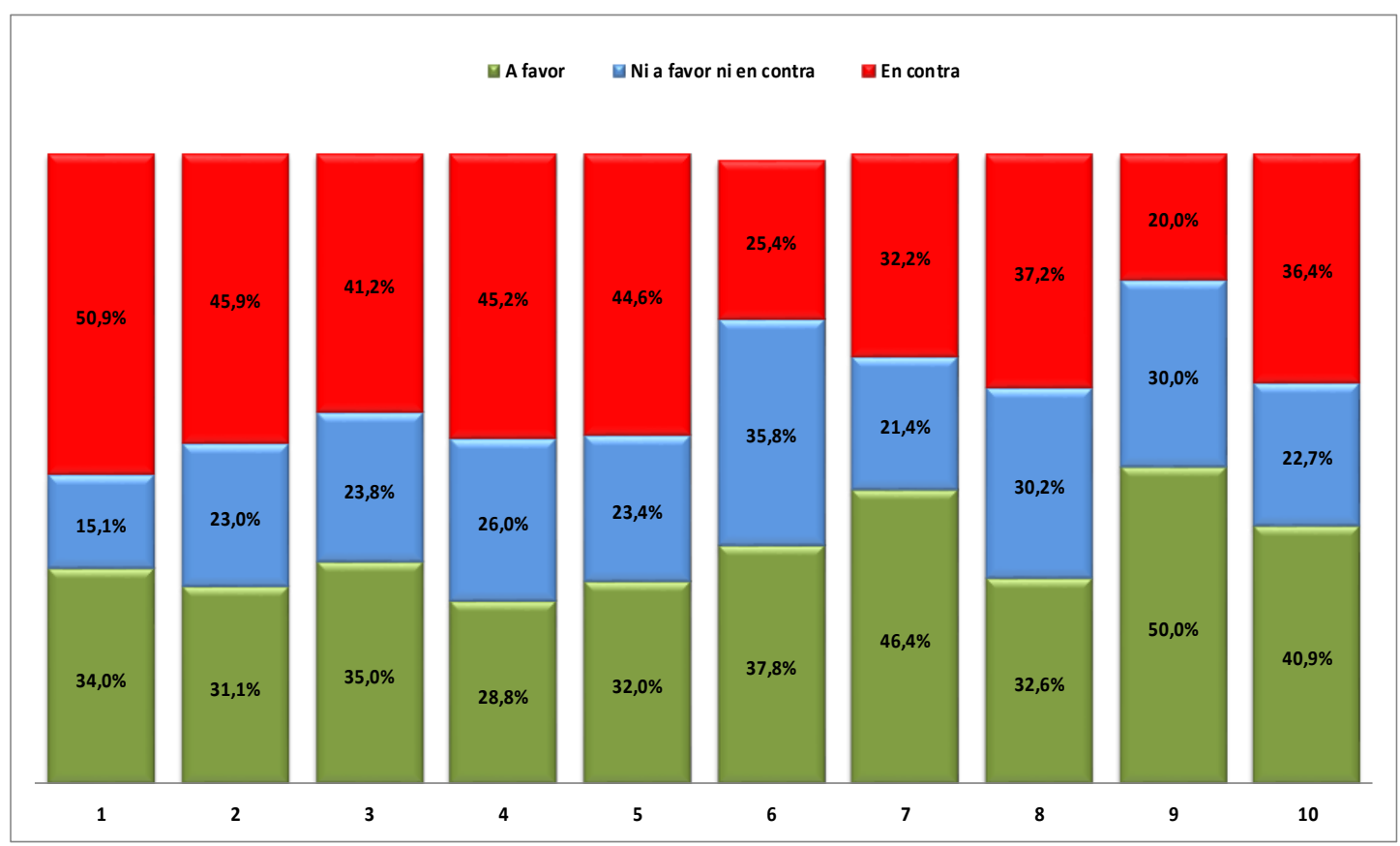

Fuente: Elaboración propia a partir de los datos obtenidos de la ERSA.

Gráfico 10: Relación entre el grado de confianza en los demás y la disposición al pago en las mujeres.

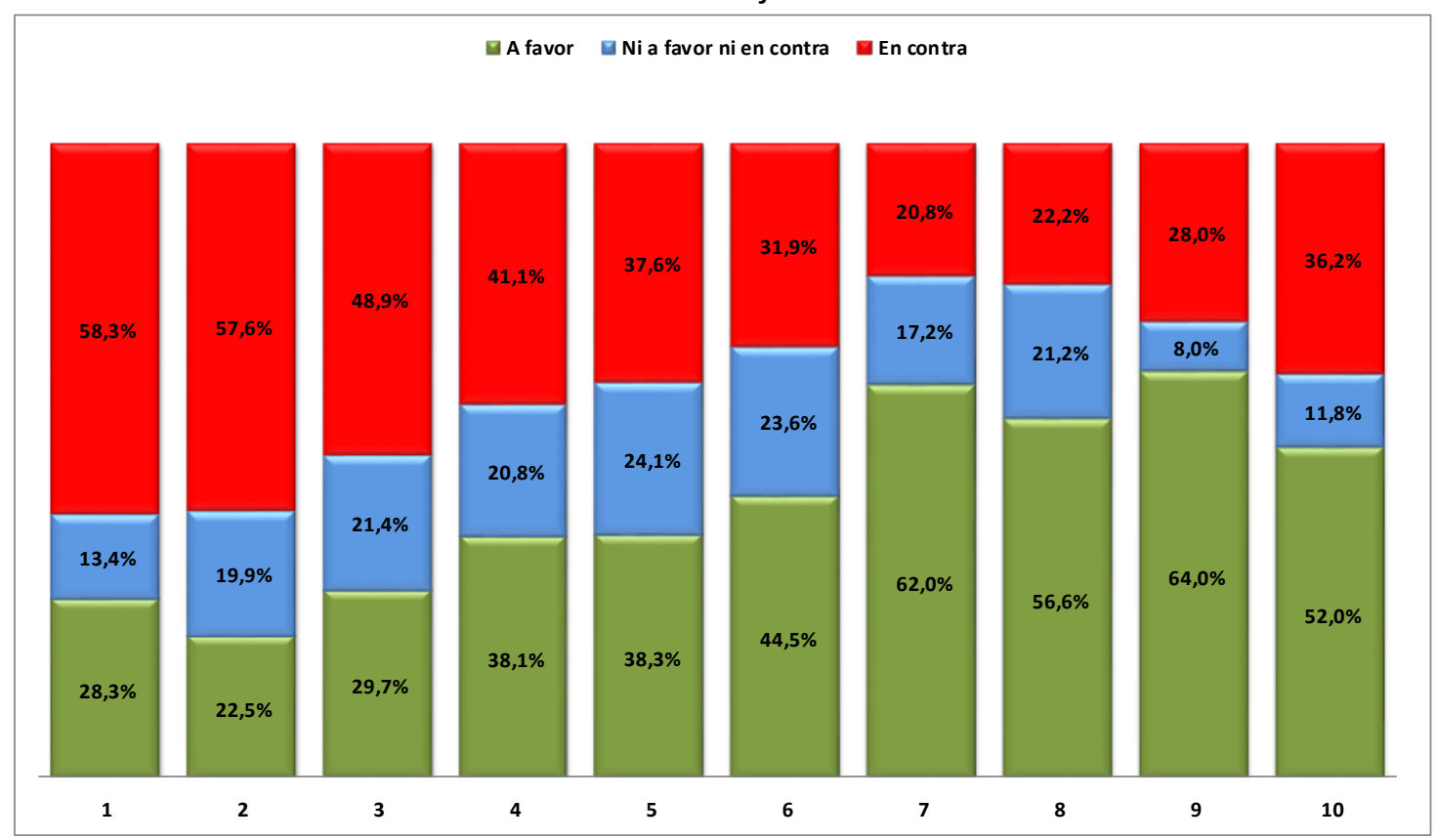

Fuente: Elaboración propia a partir de los datos obtenidos de la ERSA.

Revista de Estudios Andaluces, vol. 34, núm. 1 (2017) pp. 1-25. e-ISSN: 2340-2776 http://dx.doi.org/10.12795/rea.2017.i34.01

\section{c) (i) (3)}

SinObraDerivada 4.0 Internacional 
la persona encuestada que se sitúe en una escala del 1 a 10, en la que 1 significa "nunca se es lo bastante prudente" y 10 significa que "se puede confiar en la mayoría de la gente".

Dada la complejidad de las tablas obtenidas, visualizaremos la situación en los gráficos siguientes. Si existe relación entre las variables implicadas esperamos que para la valoración de 1 a 3 (Poca o ninguna confianza), la zona roja sea mayor que la verde. Mientras que para la valoración de 8 a 10 (Mucha o total confianza), sea mayor la zona verde que la roja. En ambos gráficos se verifican estas correspondencias.

Procediendo al análisis estadístico encontramos que efectivamente existen correlaciones negativas entre el grado de confianza en los demás y la disposición al pago, pero no significativas al $95 \%$ en los hombres (Coeficiente de correlación $=-0,074$ $p=0,071$ ) y sí en las mujeres (Coeficiente de correlación $=-0,197 p<0,01$ ). Este hecho puede estar relacionado con la diferencia existente entre el capital social de hombres y mujeres de Andalucía. La base de datos utilizada no permite profundizar, como sería deseable, en esta cuestión.

\section{CONCLUSIONES}

A lo largo del análisis de los resultados de las encuestas analizadas hemos visto que aunque la preocupación por los temas medioambientales es alta en la población andaluza. Tanto hombres como mujeres manifiestan que no se debería disminuir el gasto público destinado al Medioambiente, sin embargo, esto resulta contradictorio cuando, a nivel individual declaran que no están dispuestos a pagar un precio más elevado para protegerlo. Por tanto, los análisis realizados nos llevan a aceptar nuestra primera hipótesis de partida: existe un gap entre la preocupación medioambiental y la predisposición a contribuir monetariamente a la sostenibilidad medioambiental, ya sea vía aumento de precios o vía aumento de impuestos. Las mismas personas que opinan que el Estado debería gastar mucho más o más en la protección del medioambiente, no piensan que se deba aumentar los precios en un porcentaje aproximado al $68 \%$ ( $81 \%$ en hombres y $45 \%$ en mujeres), y no piensan que deban aumentarse los impuestos en un porcentaje aproximado al $47 \%$ (29\% en hombres y $45 \%$ en mujeres).

Estos resultados tan dispares respecto a precio e impuestos nos llevan a no poder ser contundentes con la segunda hipótesis de partida, los hombres y mujeres se comportan de manera significativamente diferente cuando deben "atenuar" su preocupación por el medioambiente vía precios, pero no cuando es vía impuestos. Esto nos lleva a profundizar en las posibles características socioeconómicas que los hace diferentes. De las variables analizadas, encontramos que tres de ellas "ingresos de la unidad familiar", "percepción sobre el deterioro medioambiental" y "grado de confianza en los demás" afectan a estas posiciones sobre la predisposición individual al pago por el cuidado del medioambiente. Sin embargo, la variable "ideología política", que para numerosos

Revista de Estudios Andaluces, vol. 34, núm. 1 (2017) pp. 1-25. e-ISSN: 2340-2776 http://dx.doi.org/10.12795/rea.2017.i34.01

$$
\text { (c) }(1)(9)
$$


autores es determinante, en el estudio realizado no es significativa para la disposición al pago.

Junto con las conclusiones extraídas debemos señalar que éstas deben restringirse a la Comunidad Autónoma de Andalucía, para la cual se dispone de datos que nos han permitido profundizar en los análisis, y no pueden extrapolarse a todo el territorio nacional pues, a pesar de ser una de las Comunidades más pobladas, el tamaño de la muestra extraída en la misma no lo permite. Sería interesante disponer de una base de datos a nivel nacional en la que pudiera llegarse a conclusiones más generales, e, incluso, poder comparar unas Comunidades con otras.

\section{REFERENCIAS}

Aguilera KlinK, F. y Alcántara V. (comp.) (1994):.De la Economía ambiental a la economía ecológica. Barcelona: ICARIA: FUHEM (2011, edición electrónica revisada, CIP-Ecosocial).

Arrow, K., Dasgupta, P., Goulder, L., Daily, G., Ehrlich, P., Heal, G., Levin, S., Mäler, K. G., Schneider, S., Starrett, D. \& Walker, B. (2004). Are we Consuming Too Much. Journal of Economic Perspectives 18, № 3, (147-172).

https://doi.org/10.1257/0895330042162377

Asián-Chaves, R. (2013). La equidad de género condición ineludible para una economía sostenible. En el I Congreso Internacional sobre sustentabilidad, competitividad y género en las organizaciones organizado por la Universidad de Sinaloa y celebrado en Mazatlán (México) los días 2 y 3 de mayo de 2013.

Castillo, A., Echavarren, J. Mạ., y Herrera-Usagre, M. (2011). La disposición a pagar por el medioambiente. Un análisis con datos de Andalucía. Fundación Pública Andaluza Centro de Estudios Andaluces. Consejería de la Presidencia. Junta de Andalucía.

Dietz, T., Kalof, L. and Stern, P. (2002).Gender, Values and Environmentalism. Social Science Quarterly 83, 1, (353-364).

Gil, J., Rodriguez, J. y Perera, V.H. (2011). Introducción al tratamiento estadístico de datos mediante SPSS. ARIAL, Sevilla.

Ecobarómetro de Andalucía (2009). Dirección General de Desarrollo Sostenible e Información Ambiental. Consejería de Medioambiente. Junta de Andalucía.

Revista de Estudios Andaluces, vol. 34, núm. 1 (2017) pp. 1-25. e-ISSN: 2340-2776

http://dx.doi.org/10.12795/rea.2017.i34.01

\section{c) (i) (3)}

SinObraDerivada 4.0 Internacional 
Encuesta sobre Realidad Social en Andalucía (ERSA). Oleada 2009. Fundación Pública Centro de Estudios Andaluces. III. Bloque de medioambiente (módulo rotatorio). [en línea: www.centrodeestudiosandaluces.es].

Freeman, A. M., Camino, V., Boucher, F., Ehrlich, P. R., Ehrlich, A. H., Pachauri, R. K., \& Mattuella, J. L. (1992). The measurement of environmental and resource values: theory and methods (No. GTZ-1574). Secretaria do Panejamento, Ciência e Tecnologia (SEPLANTEC), Bahía (Brasil). IICA, Brasilia (Brasil).

González, A. (2005). La preocupación por la calidad del medioambiente. Un modelo cognitivo sobre la conducta ecológica. España: Universidad Complutense de Madrid.

Jürgen Meyerhoff, Ulf Liebe. (2006). Protest beliefs in contingent valuation: explaining their motivation. Ecological Economics 57 (4), 583-594.

https://doi.org/10.1016/j.ecolecon.2005.04.021

Lebart, L.; Morineau, A, et Fenelon, J.P. (1985): Tratamiento estadístico de datos. Ed. Dunod. Paris.

Levy, C. (1992).Gender and the environment: the challenge of cross-cutting issues in development policy and planning. Environment and Urbanization, vol. 4, № 1, abril. https://doi.org/10.1177/095624789200400114

Mellor, M. (2002). Género y medioambiente. En Redclift y Woodgate (Eds.) Sociología del medioambiente: una perspectiva internacional. España: Editorial McGraw-Hill, pp. 193-203.

Middlestadt, S., Grieser, M.; Hernández, O. Tubaishat, K, Sanchack, J., Southwell, B., \& Schwartz, R. (2001).Turning minds on and faucets off: Water conservation education in Jordanian schools. The Journal of Environmental Education, 32(2): 37-45. https://doi.org/10.1080/00958960109599136

Mostafa, M. (2007).Gender differences in Egyptian consumers' green purchase behaviour: the effects of environmental knowledge, concern and attitude. International Journal of Consumer Studies 31 (3), 220-229.

https://doi.org/10.1111/j.1470-6431.2006.00523.x

Naciones Unidas (1992). Declaración de Río sobre el Medioambiente y el Desarrollo. Informe de la Conferencia de Naciones Unidas sobre Medioambiente y Desarrollo (A/CONF.151/26), vol. 1, Nueva York.

OCDE Environmental Policies and Economic Performance14 March 2016

Revista de Estudios Andaluces, vol. 34, núm. 1 (2017) pp. 1-25. e-ISSN: 2340-2776 http://dx.doi.org/10.12795/rea.2017.i34.01 
Osorio Hernández, C. (2010). Gênero e Meio Ambiente: A construção do discurso para o Desenvolvimento Sustentable. En Ambiente y Desarrollo Vol. XIV, n 26, enero-junio 2010, Bogotá (Colombia), páginas 13-33.

Rico, M. N. (1998). Género, Medioambiente y Sustentabilidad del Desarrollo.Unidad Mujer y Desarrollo de la CEPAL. Santiago de Chile.

Ruiz-Maya, L y Martín-Pliego, J. (2005). Fundamentos de Inferencia Estadística (3a ed.), Ediciones Paraninfo, S.A.

Stern, P. (1993).Value Orientations, Gender, and Environmental Concern. Environment and Behavior, 25 (3), 322-348. 